\title{
The Crystal Structure of $\beta^{\prime}$ Martensite in Cu-Al Binary Alloys
}

\author{
By Norihiko Nakanishi*
}

\begin{abstract}
It has been reported preiviously that an ordering reaction, the $\beta \rightarrow \beta_{1}$ transformation, occurs first, followed by a martensitic transformation, $\beta_{1} \rightarrow \beta^{\prime}$, on rapid cooling from the $\beta$ region in Cu-Al binary alloys. The possibility of this transformation process has also been observed in the case of isothermal transformation by means of dilatometric, electric resistance, and specific heat measurements. In order to determine the crystal structure of the $\beta^{\prime}$ martensite with ordered configuration, a powdered specimen containing 24.06 at $\% \mathrm{Al}$ close to an eutectoid composition was water-quenched from $950^{\circ} \mathrm{C}$, and then analyzed by using the diffraction pattern obtained by use of an X-ray diffractometer.

The experiments showed the following results, (1) The superlattice lines observed in the diffraction pattern of $\beta^{\prime}$ martensite has proved that the $\beta_{1} \rightarrow \beta^{\prime}$ transformation retains the $\mathrm{Cu}_{3} \mathrm{Al}$ type ordering configuration, $\mathrm{Cu}_{3} \mathrm{Al}$ type, when rapidly cooled. (2) The crystal structure of the $\beta^{\prime}$ martensite is a distorted hexagonal closepacked structure, in which the (0001) direction makes an angle of about $3^{\circ}$ to the normal (0001) plane. The results obtained have been discussed with the martensitic transformations of $\mathrm{Cu}-\mathrm{Al}, \mathrm{Cu}-\mathrm{Zn}$, and $\mathrm{Cu}-\mathrm{Sn}$ binary alloys and the similarity of the crystal structure and habit plane.
\end{abstract}

(Received December 23, 1960)

\section{Introduction}

It has been reported previously that in $\mathrm{Cu}-\mathrm{Al}$ alloys in the composition range from 11 to $13.1 \mathrm{wt} \% \mathrm{Al}$, an ordering reaction, $\beta \rightarrow \beta_{1}$, occurs, followed by a martensitic transformation, i. e. $\beta_{1} \rightarrow \beta^{\prime}$. The structure of the ordered $\beta_{1}$ phase was first proposed by Wassermann, (1)

* University of Osaka Prefecture, Faculty of Engineering, Department of Metals Engineering, Sakaishi, Japan. to be the $\mathrm{Fe}_{3} \mathrm{Al}$ type, and its unit cell has a twice that lattice parameter of $\beta$ (disordered b.c.c. phase). Some points about regarding the crystal structure of the martensites have been clear recently. (1) The crystal structure of the martensite changes with the $\mathrm{Al}$ concentration, i. e., the $\beta^{\prime}$ martensite occurs in the range between ca 11 and $13.1 \mathrm{wt} \% \mathrm{Al}$ (22.55 and 26.20 at

(1) G. Wasseermann: Metallwirt., 13 (1934), 133. 
$\% \mathrm{Al}$ ) and the $\gamma^{\prime}$ martensite occurs in the range between ca 12.9 and $14.7 \mathrm{wt} \% \mathrm{Al}(25.86$ and 28.87 at $\% \mathrm{Al})$. (2) The $\gamma^{\prime}$ martensite, which Isaitschew èt al. (2) have determined as close-packed hexagonal, has lattice parameters (for 13.6 wt \% Al) $a=2.606 \AA, c / a=1.619$. (3) The $\beta^{\prime}$ structure, on the other hand, is little known. Obinata ${ }^{(3)}$ has obtained X-ray diffraction photographs of the $\beta^{\prime}$ martensite in powdered specimens containing $12.5 \mathrm{wt} \% \mathrm{Al}(25.17$ at $\% \mathrm{Al})$ and reported that this martensite is a mixed phase with a hexagonal $\beta^{\prime}$ phase which has lattice parametters $a=11.13 \AA, c=6.342 \AA$, and $c / a=0.5698$ and an ordered $\beta$ phase, which is a body-centred-cubic lattice with a parameter $a=$ $5.835 \AA$. On the contrary, Bradley and Jones (4) have reported that the $\beta^{\prime}$ martensite consists of single phase, and its structure is analogous to that of the $\alpha$ phase because many diffraction lines are observed twice at the same positions on the diffraction pattern.

Wassermann ${ }^{(1)}$ has recognized that $\beta^{\prime}$ is analogous to $\alpha$ too. On the other hand, Isaitechew et al. (2) have reported that the lattice of $\beta^{\prime}$ differs from $\gamma^{\prime}$ and is described in such a way that the [00.1] direction makes an angle of $2^{\circ}$ to the $(00.1)$ normal plane and the angle between the planes (10.0) and (01.0) differs by about $1^{\circ}$ from $120^{\circ}$. Greninger ${ }^{(5)}$ has proposed that the former angle is $1^{\circ} \pm \frac{1}{2}^{\circ}$ and the latter $0^{\circ} \pm \frac{1}{2}^{\circ}$ from the Laue back-reflection and the oscillation methods. (4) It has also been reported ${ }^{(5)}$ that the $\beta^{\prime}$ and $\gamma^{\prime}$ lattices must be closely related, judging from the experimental fact that these two are changed by plastic deformation from one to the other.

The author previously investigated the behavior of the $\beta_{1} \rightleftarrows \beta^{\prime}$ transformation in both the isothermal and the tempering processes by means of dilatometric, electric resistance, and specific heat measurements, ${ }^{(6)}$ and it was conceivable that the ordering structure, $\beta_{1}$, plays an important role in elucidating the transformation kinetics and the crystal structure of the $\beta^{\prime}$ martensite.

First in the present experiment, a powder diffraction pattern of the $\beta^{\prime}$ martensite was obtained, and the process of the $\beta \rightarrow \beta_{1} \rightarrow \beta^{\prime}$ transformation by rapid cooling was confirmed by an analysis of the superlattice lines observed in the pattern. Secondly the lattice spacings and the diffraction line intensities were calculated assuming a monoclinic or a triclinic lattice for the $\beta^{\prime}$ martensite, and the results were compared with those observed.

\section{Experimental Methods}

The chemical composition of the specimen is shown in Table 1. Afler the bulk alloy had been prepared, it was filed. The filings were passed through a sieve of 300 mesh, put in a quartz-tube; and water-quenched from $950^{\circ} \mathrm{C}$. The quenching treatment was done in $\mathrm{N}_{2}+\mathrm{H}_{2}$ atmosphere produced by thermal decomposition

(2) I. Isaitschew, E. Kaminsky, and G. Kurdjumov: Trans. AIME, 128 (1938), 361.

(3) Obinata : Memoirs, Ryojun College of Eng., 3 (1931), 285.

(4) A. J. Bradley and P. Jones: J. Inst. Metals, 51 (1933), 131.

(5) A. B.'Greninger: Trans. AIME, 133 (1939), 204.

(6) Mitani and Nakanishi: J. Japan Inst. ¿Metals, 22 (1958), $208 ; 23(1959), 48$, and under printing. of anhydrous ammonia.

The diffraction pattern of the quenched specimen was obtained in the angular range of $2 \theta$ between 10 and $150^{\circ}$ by means of an X-ray diffractometer, using $\mathrm{Cu} K \alpha$ radiation filtered by $\mathrm{Ni}$. In order to examine

Table 1 Chemical composition of the specimen.

\begin{tabular}{l|c|c|c|c}
\hline \hline Al at \% & Al wt \% & Fe wt \% & Si wt \% & Cu wt \% \\
\hline 24.06 & 11.86 & 0.05 & - & Bal. \\
\hline
\end{tabular}

profiles in detail, the "Fixed-Count" method was applied to some diffraction lines belonging to the h.c.p. structure, i.e. $(11 \overline{2} 0),(10 \overline{1} 3),(11 \overline{2} 2)$, and $(20 \overline{2} 3)$. Although the observed pattern does not show the h.c.p. structure but a complicated one as shown in Fig 4 (c), the author has tentatively used the hexagonal indices, and found that the lines, $(10 \overline{1} 0),(0002),(11 \overline{2} 0),(11 \overline{2} 2)$, and (0004), appeared at the almost reasonable h.c.p.

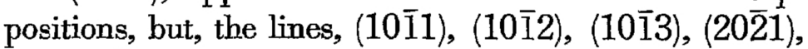
and (202̄3), split into two peaks.*

\section{Experimental Results}

\section{On the superlattice lines}

As the superlattice lines were always observed on the $\mathrm{X}$-ray diffraction pattern of the martensite formed by rapid-quenching, it was assumed that the $\mathrm{Cu}_{3} \mathrm{Al}$ ordered structure was retained in the process of the $\beta_{1} \rightarrow \beta^{\prime}$ transformation, and then the lattice relationship between b.c.c. and h.c.p. proposed by Burgers for $\mathrm{Zr}$, (7)

$$
\begin{aligned}
& (110) \text { b.c.c. } / /(0001) \text { h.c.p. } \\
& {[\overline{1} 11] \text { b.c.c. } / /[11 \overline{2} 0\rceil \text { h.c.p., }}
\end{aligned}
$$

was applied to the $\beta_{1} \rightarrow \beta^{\prime}$ transformation. This is shown in Fig. 1 (A), (B). Translating the h.c.p structure into an orthorhombic structure for the convenience of the calculation of the structure factor, as shown in Fig. $1(\mathrm{C})$, the positions occupied respectively by $\mathrm{Al}$ and $\mathrm{Cu}$ atoms are as follows:

$$
\begin{aligned}
& \text { Al: } \theta 00, \frac{1}{3} \frac{1}{2} \frac{1}{2} \text { or } 000, \frac{2}{3} \frac{1}{2} \frac{1}{2} \\
& \mathrm{Cu}: \frac{1}{2} \frac{1}{4} 0, \frac{1}{2} \frac{3}{4} 0,0 \frac{1}{2} 0, \frac{1}{3} 0 \frac{1}{2}, \frac{5}{6} \frac{1}{4}, \frac{5}{2} \frac{3}{4} \frac{1}{2} \\
& \text { or } \frac{1}{2} \frac{1}{4} 0, \frac{1}{2} \frac{3}{4} 0 ; 0 \frac{1}{2} 0, \frac{2}{3} 0 \frac{1}{2}, \frac{1}{6} \frac{1}{4} \frac{1}{2}, \frac{13}{6} \frac{1}{4}
\end{aligned}
$$

then the structure factor, F, can be described as follows:

$$
\begin{aligned}
\mathrm{F}=\left[1+\mathrm{e}^{2 \pi^{i}\left(\frac{2}{3} h+\frac{k}{2}+\frac{l}{2}\right)}\right]\left[f_{A l}-f_{C u}\right. \\
\left.+f_{C u}\left(1+2 \cos \pi h \cdot \cos \frac{\pi k}{2}+\cos \pi k\right)\right]
\end{aligned}
$$

where $f_{A l}$ and $f_{C u}$ are the atomic scattering factors of $\mathrm{Al}$ and $\mathrm{Cu}$ atoms, respectively. Based on this expression it is to be seen that the superlattice lines will be observed in the following four cases:

* A notable broadening is observed in the splitting lines of (1012).

(7) W. G. Burgers : Physica, 1 (1934), 561. 


$$
\begin{array}{lll}
h=2 n, & k=4 n \pm 1, & \mathrm{~F}=f_{A l}-f_{C u}, \\
h=2 n, & k=4 n \pm 2, & \mathrm{~F}=f_{A l}-f_{C u}, \\
h=2 n+1, & k=4 n, & \mathrm{~F}=f_{A l}-f_{C u,} \\
h=2 n+1, & k=4 n \pm 1, & \mathrm{~F}=f_{A l}-f_{C u s}
\end{array}
$$

The calculated values of lattice spacings are shown in comparison with the observed ones in Table $2 . \quad$ There

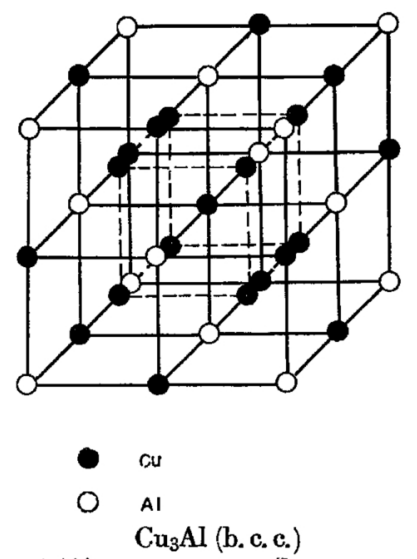

Fig. 1 (A) $\beta_{1}$ structure (by wassermann)

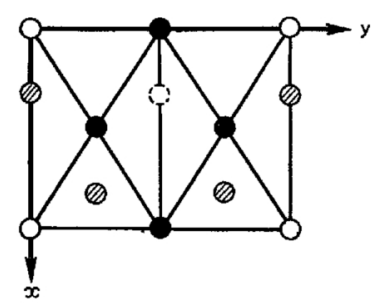

\begin{tabular}{|c|c|c|c|c|}
\hline $\begin{array}{c}\text { Orthorhombic } \\
\text { indices }\end{array}$ & $\begin{array}{l}\text { Hexagonal } \\
\text { indices }\end{array}$ & $|F|$ & $d_{\text {calc. }}$ & $d_{\text {obs. }}$ \\
\hline$(100)$ & $\left(\frac{1}{2} 0.0\right)$ & $\mid 1 \cdot\left(f_{\mathrm{Al}}-f_{\mathrm{Cu}}\right)$ & 4.4995 & .4 .5063 \\
\hline (110) & $\left(\frac{1}{4} \frac{1}{2} \cdot 0\right)$ & $\sqrt{3} \cdot(")$ & 3.4025 & 3.4012 \\
\hline (011) & $\left(\frac{1}{4} \frac{1}{2} \cdot 1\right)$ & $2 \cdot(")$ & 3.2867 & 3.2903 \\
\hline (101) & $\left(\frac{1}{2} 0.1\right)$ & $\sqrt{3} \cdot(")$, & 3.0872 & 3.1815 \\
\hline (111) & $\left(\frac{1}{4} \frac{1}{2} .1\right)$ & $1 \cdot(")$ & 2.6542 & 2.6749 \\
\hline (020) & $\left(\frac{1}{2} 1.0\right)$ & $2 \cdot(11)$ & 2.5981 & 2.6069 \\
\hline (102) & $\left(\frac{1}{2} 0.2\right)$ & $1 \cdot(")$ & 1.9208 & 2.5926 \\
\hline (112) & $\left(\frac{1}{4} \frac{1}{2} \cdot 2\right)$ & $\sqrt{3} \cdot(19)$ & 1.8005 & $\begin{array}{l}1.0000 \\
1.7776\end{array}$ \\
\hline$(220)$ & $\left(\frac{1}{2} 1.0\right)$ & $1 \cdot(\cdot 3)$ & 1.7009 & 1.7068 \\
\hline (022) & $\left(\frac{1}{2} 1.2\right)$ & $2 \cdot(\mathrm{l})$ & $1: 6436$ & 1.6420 \\
\hline (221) & $\left(\frac{1}{2} 1.1\right)$ & $\sqrt{3} \cdot(1 ")$ & 1.5784 & $\left\{\begin{array}{l}1.6027 \\
1.5512\end{array}\right.$ \\
\hline$(230)$ & $\left(\frac{1}{4} \frac{3}{2} \cdot 0\right)$ & $\sqrt{3} \cdot(")$ & 1.3726 . & 1.3750 \\
\hline (013) & $\left(\frac{1}{4} \frac{1}{2} ; 3\right)$ & $2 \cdot(\cdot 1)$ & 1.3648 & 1.3645 \\
\hline (103) & $\left(\frac{1}{2} 0.3\right)$ & $\sqrt{3} \cdot(1)$ & 1.3496 & $\left\{\begin{array}{l}1.3542 \\
1.3275\end{array}\right.$ \\
\hline (222) & $\left(\frac{1}{2} 1.2\right)$ & $1 \cdot(" 1)$ & .7 .3273 & 1.3267 \\
\hline (113) & $\left(\frac{1}{4} \frac{1}{2}, 3\right)$ & $1 \cdot(")$ & 1.3065 & $\left\{\begin{array}{l}1.3183 \\
1.2914\end{array}\right.$ \\
\hline (231) & $\left(\frac{1}{4} \frac{3}{2}, 1\right)$ & $1 \cdot(\%)$ & 1.3063 & 1.2824 \\
\hline
\end{tabular}

$$
\begin{array}{ll}
\text { Gu } & \text { Al } \\
0 & 0
\end{array}
$$

Fig. 1 (C) Orthorhombic lattice

Table 2 Superlattice lines in the pattern.

is good agreement between the calculation and observation. However, the $\beta^{\prime}$ structure is not h.c.p. as described in the next section, and so the calculated spacings illustrated in Table 2 should be split. The splitting of the main lines are in fact shown in the observed pattern of Fig. 4 (C)

2. On the Structure models with a monclinic lattice or a triclinic lattice assumed for the $\beta^{\prime}$ structure

Considering the observed facts that a splitting of the

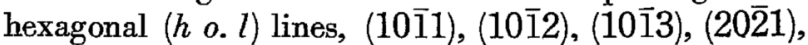

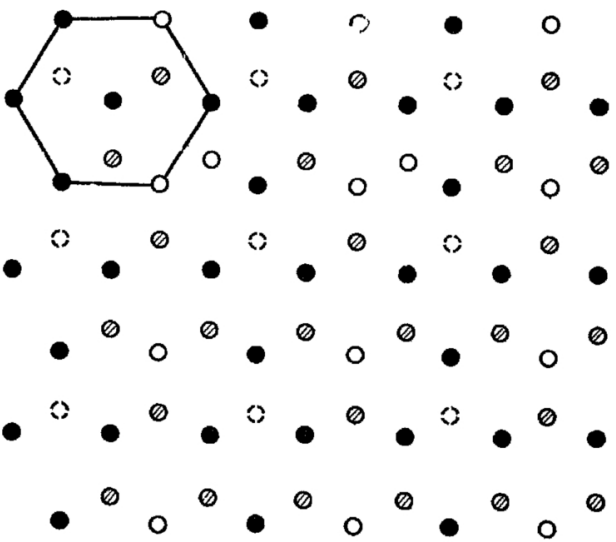

$$
\begin{aligned}
& \text { Cu Al } \quad \text { a toms in ocd planes } \\
& \text { - O atoms in even planes } \\
& \mathrm{Cu}_{3} \mathrm{Al} \text { (b. c. c.) } \\
& \text { Fig. } 1 \text { (B) b. c. c. } \rightarrow \text { h. c. p. }
\end{aligned}
$$

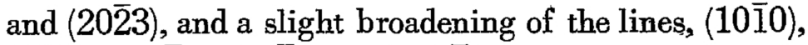
$(11 \overline{2} 0),(20 \overline{2} 0),(11 \overline{2} 2)$, and $(11 \overline{2} 4), *$ were recognized in the diffraction pattern, it may be reasonable to assume that the $\beta^{\prime}$ martensite is a distorted structure, near to hexagonal.

Therefore, (a) orthorhombic (pseudo-hexagonal), (b) monoclinic, and (c) triclinic structures were assumed for this structure and possible patterns were calculated in "trial and error" and compared with that observed.

\section{(1) Orthorhombic structure model}

First, the author assumed an orthorhombic lattice for elucidating the observed pattern which showed the above ordered structure, but the result was npt satisfactory and not in agreement with the observed pattern.

\section{(2) Monoclinic structure model}

A monoclinic lattice in which the $c$-axis inclines slightly from the normal to the basal plane of the h.c.p. structure, as shown in Figs. 2 (A) and (B), was assumed.

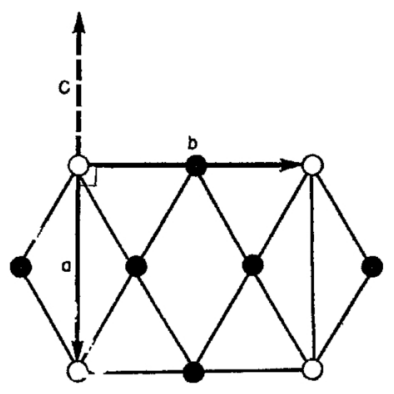

(A)

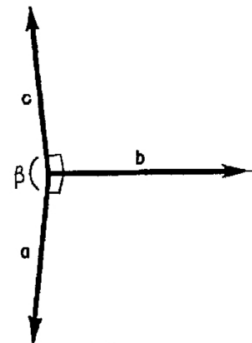

(B)
Fig. 2 monoclinic lattice.

\footnotetext{
* The splitting was also observed in $(11 \overline{2} 2)$ and $(11 \overline{2} 4)$ lines.
} 
Table 3 Relationship between the numbers of splitting and the absolute values of $F$, assuming a monoclinic lattice.

\begin{tabular}{|c|c|c|c|c|c|c|c|c|c|c|c|}
\hline $\begin{array}{l}\text { Hexagonal } \\
\text { indices }\end{array}$ & $\begin{array}{c}\text { Monoclinic } \\
\text { indices }\end{array}$ & $\begin{array}{l}\text { The numbers } \\
\text { of splitting }\end{array}$ & & & & $\begin{array}{c}\text { Hexagonal } \\
\text { indices. }\end{array}$ & $\begin{array}{c}\text { Monoclinic } \\
\text { indices }\end{array}$ & $\begin{array}{l}\text { The numbers } \\
\text { of splitting }\end{array}$ & \multicolumn{3}{|c|}{$|\mathbf{F}|$} \\
\hline$(10.0)$ & $\left\{\begin{array}{l}(200) \\
(120)\end{array}\right.$ & 2 & \multicolumn{3}{|c|}{$1 \cdot\left(f_{\mathrm{Al}}-f_{\mathrm{Cu}}+4 f_{\mathrm{Cu}}\right)$} & $(00.4)$ & $\begin{array}{l}(004) \\
(402)\end{array}$ & 1 & $2 \cdot(f$ & $f_{\mathrm{Cu}}$ & \\
\hline$(00.2)$ & $\begin{array}{r}(002) \\
(201)\end{array}$ & 1 & $2 \cdot($ & $"$ & ) & $(20.2)$ & $\left(\frac{242}{242}\right)$ & 4 & $1 \cdot($ & " & ) \\
\hline$(10.1)$ & (121) & 4 & $\sqrt{3 \cdot 1}$ & $"$ & 1 & & $\begin{array}{l}(\overline{4} 02) \\
(204)\end{array}$ & & & & \\
\hline$(10.2)$ & $\begin{array}{l}(\overline{2} 01) \\
(202) \\
(122) \\
(\overline{1} 22)\end{array}$ & 4 & $1 \cdot($ & $"$ & ) & $(10.4)$ & $\begin{array}{l}(124) \\
(124) \\
(204) \\
(403)\end{array}$ & 4 & $1 \cdot($ & " & ) \\
\hline$(11.0)$ & $\begin{array}{r}(202) \\
+(320) \\
(040) \\
(203)\end{array}$ & 2 & $2 \cdot 1$ & " & ) & $(20.3)$ & $\left\{\begin{array}{l}(243) \\
(243) \\
(403)\end{array}\right.$ & 4 & $\sqrt{3} \cdot 1$ & " & ) \\
\hline$(10.3)$ & $\begin{array}{l}(123) \\
(123) \\
(\overline{2} 203)\end{array}$ & 4 & $\sqrt{3} \cdot 1$ & $"$ & ) & (11.4) & $\left\{\begin{array}{l}(324) \\
(044) \\
(205)\end{array}\right.$ & \} & $2 \cdot($ & $"$ & ) \\
\hline$\langle 20.0\rangle$ & $\begin{array}{l}(400) \\
(240) \\
(322)\end{array}$ & 2 & $1 \cdot($ & $"$ & ) & $(10.5)$ & $\begin{array}{l}(125) \\
(\overline{125}) \\
(\overline{205})\end{array}$ & \} & $\sqrt{3} \cdot($ & $"$ & ) \\
\hline (11.2) & $\begin{array}{l}(322) \\
(042) \\
(401)\end{array}$ & 3 & $2 \cdot($ & $"$ & ) & & & & & & \\
\hline$(20.1)$ & $\left\{\begin{array}{l}(241) \\
(24]) \\
(401)\end{array}\right.$ & 4 & $\sqrt{3} \cdot 1$ & " & ) & & & & & & \\
\hline
\end{tabular}

Table 4 Comparison between the observed and calculated values, using parameters of the monoclinic lattice.

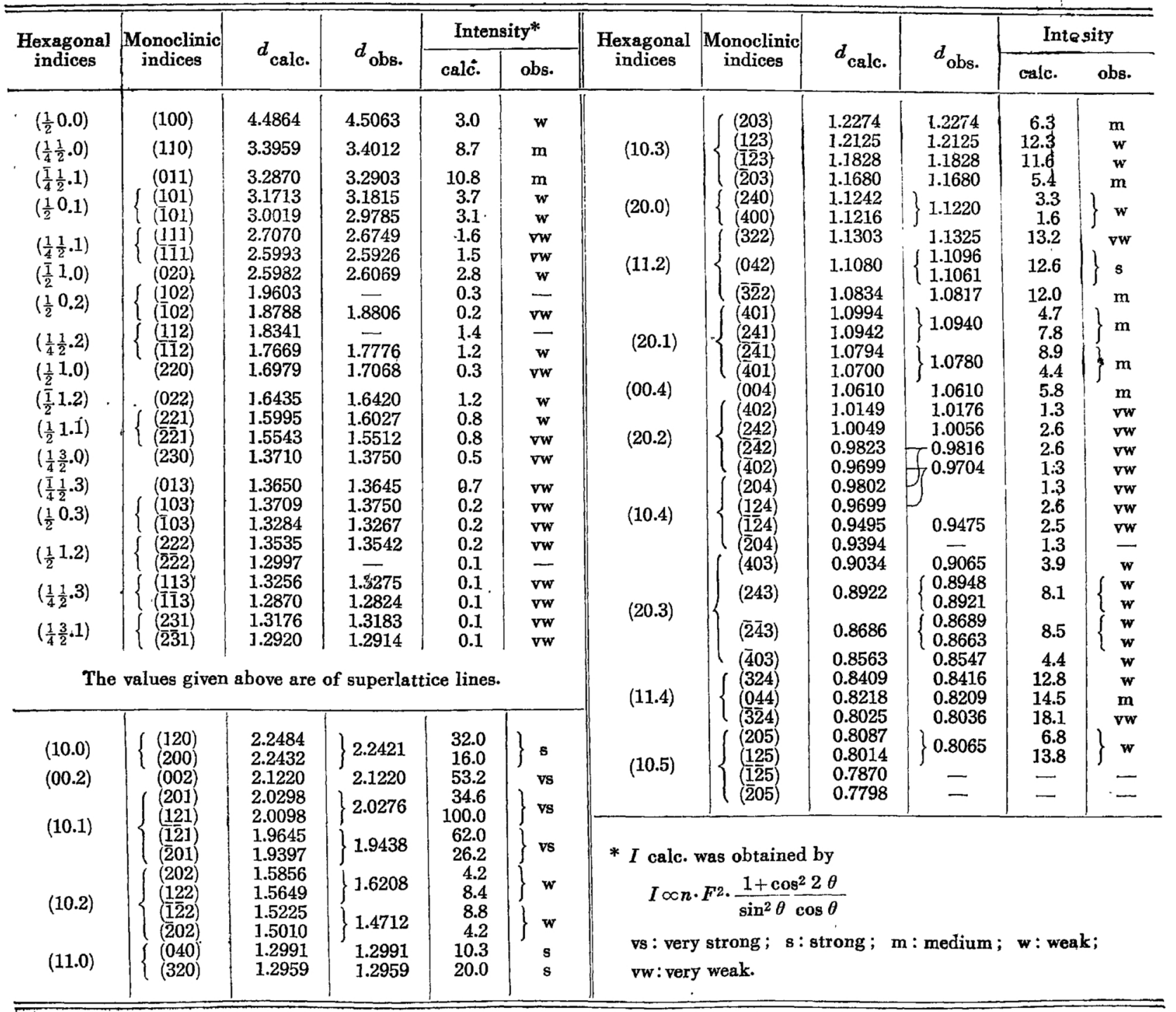


In this assumption, all lines must be split except hexagonal $(000 l)$ lines, and Table 3 shows the relationship between the $|F|$ and the splitting numbers calculated from the monoclinic model shown in Figs. 2 (A) and (B). According to this model, the main lines

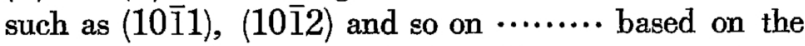
hexagonal indices are split into four peaks, such as $(10 \overline{10})$ and $(11 \overline{2} 0)$ are split into two, and such as $(11 \overline{2} 2)$ and $(11 \overline{2} 4)$ are split into three, respectively. The lattice spacings and intensities calculated by adopting $a=$ $4.493 \AA, b=5.196 \AA, c=4.250 \AA$, and $\beta=86.9^{\circ}$ as lattice parameters* were shown in Table 4 as compared with the observed values. There was a rough agreement between calculation and observation.

\section{(3) Triclinic structure model}

A triclinic lattice is assumed without fixing the direction of the inclination of the $c$-axis and with the axes of $a, b$, and $c$ and the angles of $\alpha, \beta$, and $\gamma$. However, it is probable to consider that the angle of $\alpha$ s alm sst equal to $90^{\circ}$, judging from the positions of
Table 5 shows the relationship between the $|F|$ and the splitting numbers calculated from the triclinic model as shown in Figs. 3 (A) and (B). The lattice spacings and intensities calculated by adopting as lattice parameters $a_{\mathrm{o}}=(4 a)=10.392 \AA, b_{o}=(2 b)=5.196 \AA, c_{o}=$ $4.252 \AA, \alpha_{o}=89.8^{\circ}, \beta=87.1^{\circ}$. and $\gamma=120^{\circ} \dagger$ were shown in Table 6 as compared with the observed values. In Fig. 4 (A) (B) (C), the positions of lines calculated

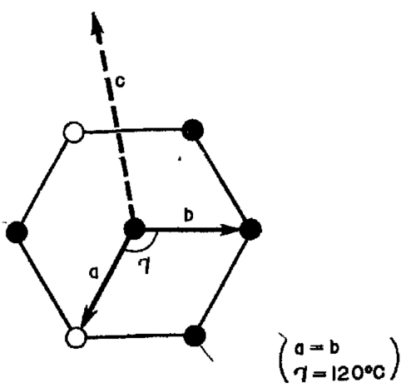

(A)

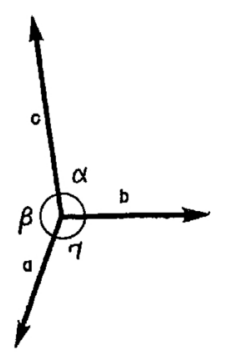

(8)
Fig. 3 Triclinic lattice.

Table 5 Relationship between the numbers of splitting and the absolute values of $F$, assuming a triclinic lattice.

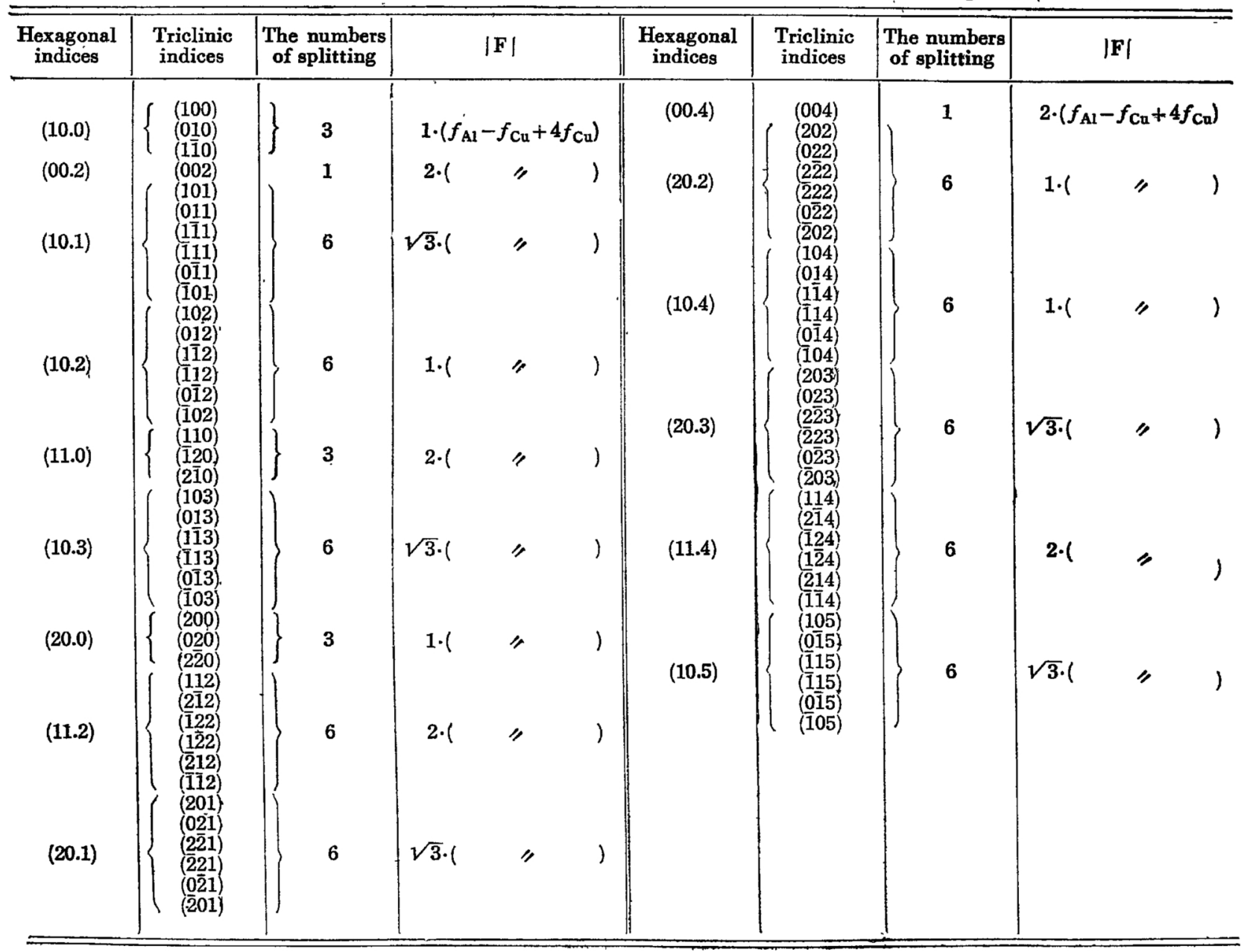

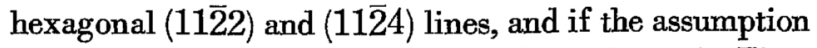
of $a=b, \gamma=120^{\circ}$ may be permitted, as shown in Figs. 3 (A) and (B), the following calculations are also permissible.

* The lattice parameters of the monoclinic lattice were selected by a "trial and error" method. in Tables 4 and 6 were compared with the observed patten. It is illustrated that the lattice spacings and intensities calculated are roughly in agreement with the observed diffraction pattern.

$\uparrow$ The lattice parameters of the triclinic lattice were also selected by a "trial and error" method. 
Strictly speaking, the above models may be thought as still incomplete because of the disagreement between calculation and observation with respect to the position of hexagonal $(10 \overline{1} 2)$ line, to the intensity of the splitting line of hexagonal (11̄22) i. e. (322) line of monoclinic, (112) and (21) lines of triclinic lattice. Thus, it is very difficult to decide which is better adapted for the observed pattern of the two models. It seems difficult to analyze more precisely the $\mathrm{X}$-ray diffraction pattern of the present martensite by the prercent method, and it is necessary to use the Laue method simultaneously for this purpose.

Table 6. Comparison between the observed and calculated values, using parameters of the Triclinic lattice.

\begin{tabular}{|c|c|c|c|c|c|c|c|c|c|c|c|}
\hline \multirow{2}{*}{$\begin{array}{l}\text { Hexagonal } \\
\text { indices }\end{array}$} & \multirow{2}{*}{$\begin{array}{c}\text { Triclinic } \\
\text { indices }\end{array}$} & \multirow{2}{*}{$d_{\text {calc. }}$} & \multirow{2}{*}{$d_{\text {obs. }}$} & \multicolumn{2}{|c|}{ Intensity* } & \multirow{2}{*}{$\begin{array}{l}\text { Hexagonal } \\
\text { indices }\end{array}$} & \multirow{2}{*}{$\begin{array}{c}\text { Triclinic } \\
\text { indices }\end{array}$} & \multirow{2}{*}{$d_{\text {calc. }}$} & \multirow{2}{*}{$d_{\text {obs. }}$} & \multicolumn{2}{|c|}{ Intensity } \\
\hline & & & & calc. & obs. & & & & & calc. & obs. \\
\hline $\begin{array}{l}\left(\frac{1}{2} 0.3\right) \\
\left(\frac{1}{2} 1.2\right) \\
\left(\frac{1}{4} \frac{1}{2} \cdot 3\right) \\
\left(\frac{1}{4} \frac{3}{2} .1\right) \\
\text { The }\end{array}$ & 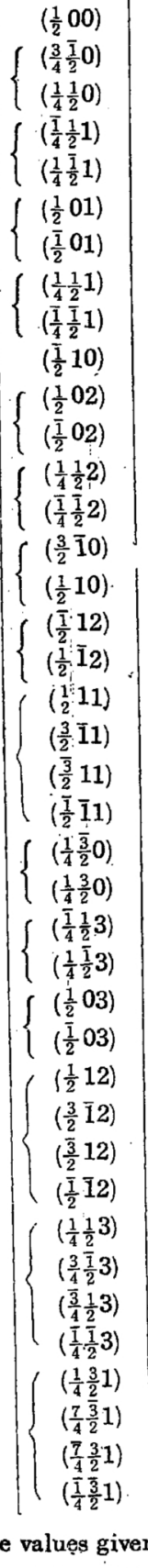 & 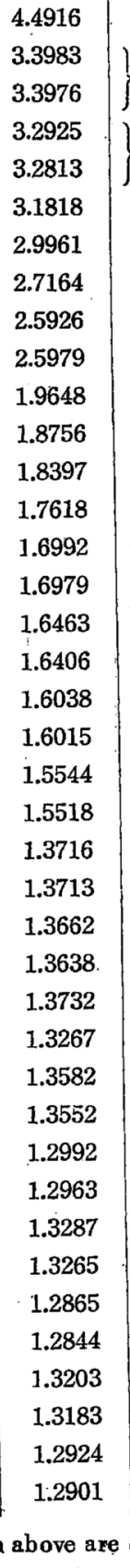 & 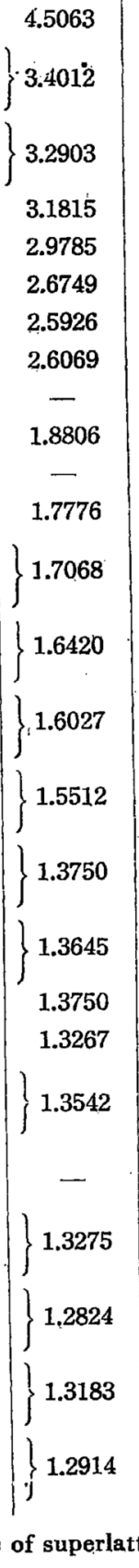 & 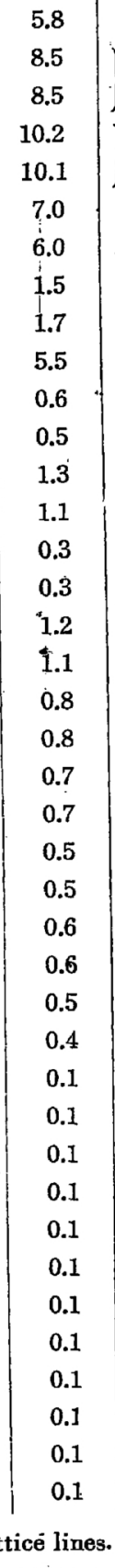 & 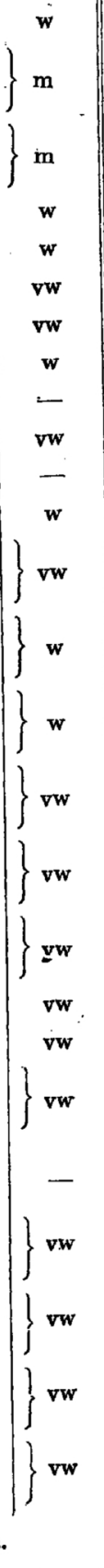 & $(00.4)$ & 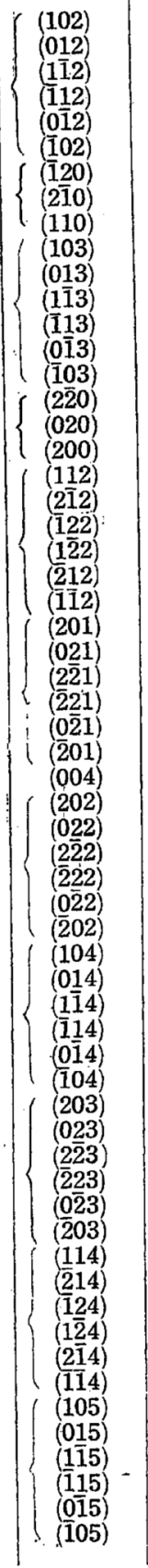 & $\begin{array}{l}1.5909 \\
1.5695 \\
1.5647 \\
1.5230 \\
1.5184 \\
1.4981 \\
1.2990 \\
1.2973 \\
1.2971 \\
1.2308 \\
1.2157 \\
1.2124 \\
1.1831 \\
1.1799 \\
1.1658 \\
1.1245 \\
1.1243 \\
1.1229 \\
1.1342 \\
1.1325 \\
1.1096 \\
1.1061 \\
1.0828 \\
1.0811 \\
1.1021 \\
1.0959 \\
1.0944 \\
1.0798 \\
1.0780 \\
1.0698 \\
1.0610 \\
1.0181 \\
1.0074 \\
1.0049 \\
0.9827 \\
0.9801 \\
0.9687 \\
0.9824 \\
0.9721 \\
0.9698 \\
0.9497 \\
0.9475 \\
0.9378 \\
0.9065 \\
0.8948 \\
0.8921 \\
0.8689 \\
0.8663 \\
0.8547 \\
0.8438 \\
0.8424 \\
0.8231 \\
0.8203 \\
0.8018 \\
0.8004 \\
0.8103 \\
0.8030 \\
0.8013 \\
0.7871 \\
0.7856 \\
0.8787\end{array}$ & 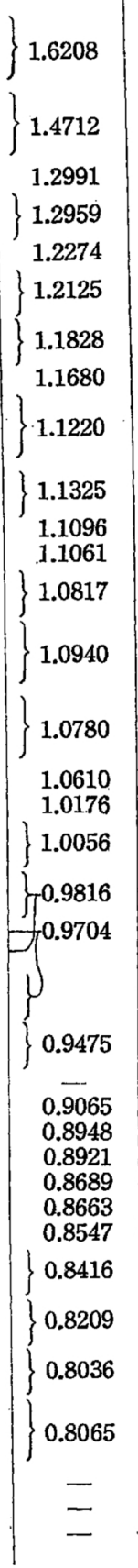 & 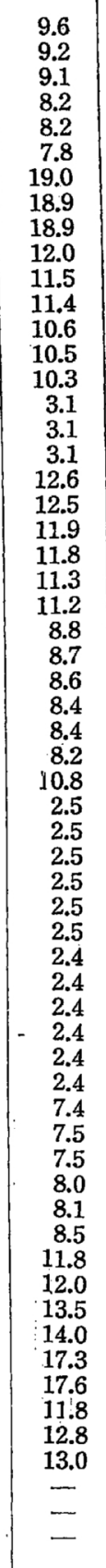 & 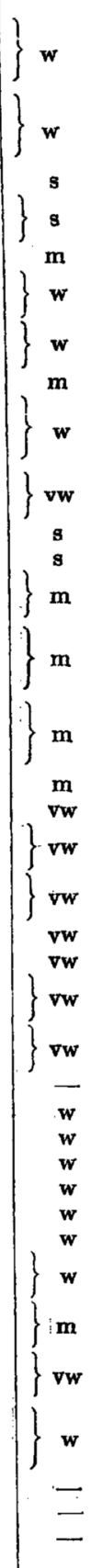 \\
\hline $\begin{array}{l}(10.0) \\
(00.2) \\
(10.1)\end{array}$ & 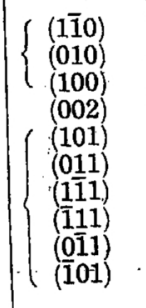 & $\begin{array}{l}2.2490 \\
2.2486 \\
2.2458 \\
2.1220 \\
2.0363 \\
2.0148 \\
2.0099 \\
1.9653 \\
1.9603 \\
1.9374\end{array}$ & $\begin{array}{l}\left\{\begin{array}{l}2.2421 \\
2.1220\end{array}\right. \\
\left\{\begin{array}{l}2.0276 \\
1.9438\end{array}\right.\end{array}$ & $\begin{array}{r}30.2 \\
30.2 \\
30.1 \\
100.0 \\
65.5 \\
63.6 \\
63.0 \\
58.3 \\
56.7 \\
55.8\end{array}$ & $\left\{\begin{array}{l}\mathrm{s} \\
\mathrm{vs} \\
\mathrm{vs} \\
\mathrm{vs}\end{array}\right.$ & $\begin{array}{r}\text { * } I \text { calc. } w \\
I= \\
\text { vs: very } \\
\text { vw: very }\end{array}$ & $\begin{array}{l}n \cdot F^{2} \cdot \frac{1+\operatorname{co}}{\sin ^{2} \theta} \\
\text { strong; }: \text { st } \\
\text { weak. }\end{array}$ & $\begin{array}{l}\text { by } \\
\frac{s^{2} 2 \theta}{\cos \theta} \\
\text { rong; } m:\end{array}$ & medium; w & weak ; & \\
\hline
\end{tabular}




\section{V. Discussion}

It has been confirmed by the agreement between calculation and observation in respect of the superlattice lines that the ordered configuration is retained in the martensite product. Therefore, it is conceivable that this ordered configuration has a profound relation to

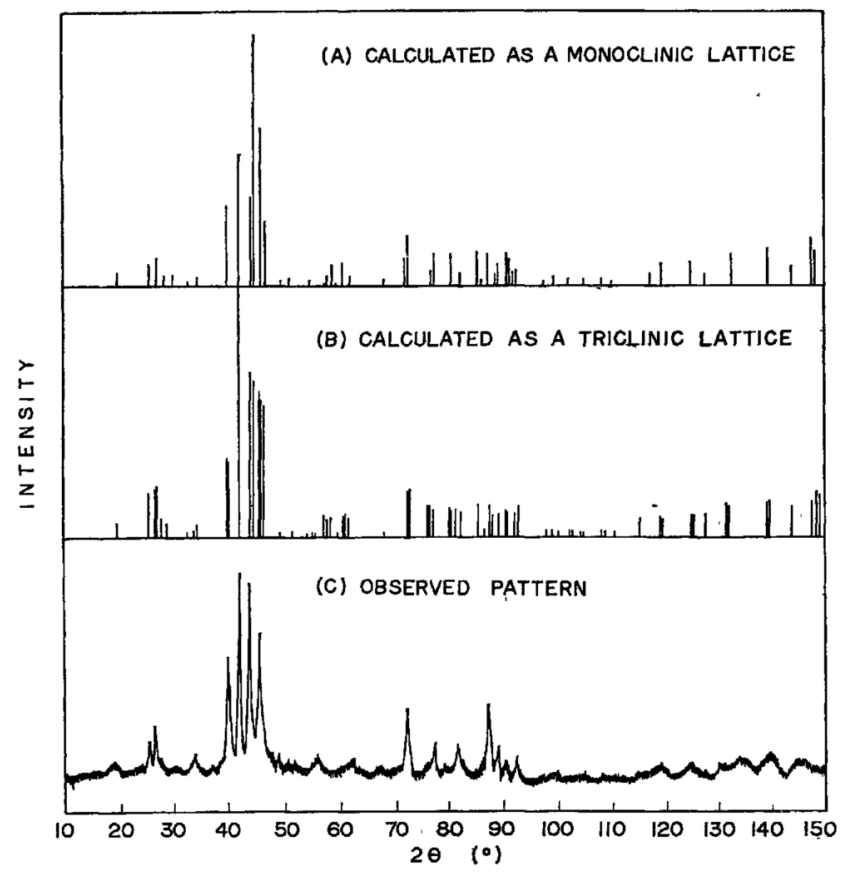

Fig. 4 Comparison between the observed patterns and calculated patterns.

the crystal structure of $\beta^{\prime}$. From the results in Tables 4 and 6 , the calculated values are almost in agreement with the observed ones concerning the splitting lines of

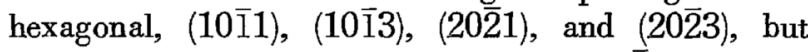
in disagreement with those concerning (10 12$)$, and the observed intensity values of splitting lines of $(11 \overline{2} 2)$ were especially lower than the calculated ones, as shown in Fig. 4 (A) (B) (C).

Although it is thought to be necessary to decide which is better of the two models, the value of $\alpha$ in the triclinic model is almost close to $90^{\circ}$, and so the difference in line breadth calculated for the two models will be within experimental error, and it is impossible to carry out the analysis more precisely owing to the broadening of lines due to the distortion caused by the formation of the martensite.

As mentioned above, the ordered structure is retained in the martensite product, and it may be reasonable to think that this ordered configuration will lead to a degeneration of the symmetry.' It will be supposed that the principal directions in the basal plane intersect no longer at $120^{\circ}$ and a similar deviation takes place in the axis normal to the basal plane if the stacking sequence is altered. The structure proposed by Isaitschew et al. is thought to be obtained as a result of the above assumptions. On the other hand, supposing the latter only, a triclinic lattice in which the $c$-axis inclines about $3^{\circ}$ from the normal to the basal plane

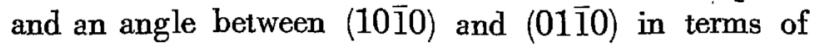
a hexagonal lattice is nearly $120^{\circ}$ is obtained as calculated by the author. Recently, Murai and Ishii ${ }^{(8)}$ have carried out an analysis of the X-ray diffraction photographs of $\beta^{\prime}$ and obtained a monoclinic structure in which the $c$-axis inclined about $2.5^{\circ}$ from the normal to the basal plane of h.c. p.. This result is closely similar to the author's.

Here the similarity between the martensite structures in $\mathrm{Cu}-\mathrm{Zn}$ and $\mathrm{Cu}-\mathrm{Sn}$ alloys and that in $\mathrm{Cu}-\mathrm{Al}$ alloy is expected, because these martensites may have the ordered structure and the similarity in the transformation mechanism is also probable.

Greninger and Mooradian ${ }^{(9)}$ have proposed that the crystal structure of the martensite in $\mathrm{Cu}-\mathrm{Zn}$ alloys is nearly face-centred tetragonal, and Garwood and Hull(10) have reported that it is the same structure as the $\beta^{\prime}$ martensite in $\mathrm{Cu}-\mathrm{Al}$ alloy and a body-centred triclinic lattice is to be obtained, as the result of a study on the orientation relationship by the Laue method. Barrett $^{(11)}$ has illustrated that a close-packed hexagonal structure with many stacking faults is produced by plastic deformation (filing) in $\mathrm{Cu}-\mathrm{Zn}$ alloys containing a higher concentration of $\mathrm{Zn}$. On the other hand, many investigations have been made on the martensite in Cu-Sn alloys, and Oainata et al., (12) Greninger and Mooradian, ${ }^{(9)}$ and Isaitschew et al. ${ }^{(2)}$ have observed that its $\mathrm{X}$-ray diffraction pattern is very analogous to that of the $\beta^{\prime}$ martensite in $\mathrm{Cu}-\mathrm{Al}$ alloys. However, the critical cooling rate for producing the martensite was so great that the transformation became more complicated, and no successful result has so far been obtained.

As mentioned above, it is obvious that the crystal structures of the martensite produced by rapid cooling are similar to each other in $\mathrm{Cu}-\mathrm{Al}, \mathrm{Cu}-\mathrm{Zn}$, and $\mathrm{Cu}-\mathrm{Sn}$ alloys. The habit planes were compared with each other and the result obtained shows that they are respectively approximately $\{133\}_{\beta}$ in $\mathrm{Cu}-\mathrm{Al}$ alloy, $\{155\}_{\beta}$ or $\{166\}_{\beta}$ in Cu-Zn alloy, and $\{133\}_{\beta}$ in $\mathrm{Cu}-\mathrm{Sn}$ alloy. The lattice orientation relationship is identical in $\mathrm{Cu}-\mathrm{Zn}$ alloy with that found in $\beta^{\prime}$ martensite of $\mathrm{Cu}$ $\mathrm{Al}$ alloy and unknown in $\mathrm{Cu}-\mathrm{Sn}$ alloy. Moreover, the martensite structure formed by cooling was recognized to be almost a triclinic lattice, and this lattice was transformed into the h.c.p. structure by plastic deformation in $\mathrm{Cu}-\mathrm{Al}$ and $\mathrm{Cu}-\mathrm{Zn}$ alloys. ${ }^{(5)}$,(11)

The fact that these martensites are produced through the ordered structure $\beta_{1}$ by cooling from the $\beta$ phase may account for the similarity in the martensite structures in these alloys. This suggests that the martensites retain the ordered configuration. This ordering reaction and the stacking faults might be considered to be responsible for the mechanisms of the transformations and for the complex crystal structures which showed the characteristics common to the $\mathrm{Cu}-\mathrm{Al}$, $\mathrm{Cu}-\mathrm{Zn}$, and $\mathrm{Cu}-\mathrm{Sn}$ alloys.

(8) Murai and Ishii : Synopsis of the 46 th Meeting of the Japan Inst. of Metals, (1960) 7.

(9) A. B. Greninger and V. G. Mooradian: Trans. AIME, 128 (1938), 337.

(10) R. D. Garwood and D. Hull : Act. Met., 6 (1958), 98.

(11) C. S. Barrett : J. of Metals, 209 (1957), 455.

(12) Obinata and Imai : Memoirs, Ryojun College of Eng., 3 (1930), 117. 


\section{Conclusions}

The author has obtained an X-ray diffraction pattern of the water-quenched martensite in the 24.06 at $\%$ $\mathrm{Al}-\mathrm{Cu}$ alloy, and has tried to determine the crystal structure of the $\beta^{\prime}$ martensite by analysing the pattern. The results are as follows:

(1) An ordered structure observed in the diffraction pattern of the $\beta^{\prime}$ martensite suggests that the ordered configuration, $\mathrm{Cu}_{3} \mathrm{Al}$, is retained in the martensite product and leads to a degeneration of the symmetry.

(2) . (a) If a monoclinic structure is assumed, the $\beta^{\prime}$ structure must have a unit cell with $a=4.493 \AA, b=$ $5.196 \AA, c=4.250 \AA$, and $\beta^{\prime}=86.9^{\circ}$. (b) If a triclinic structure is assumed, the $\beta^{\prime}$ structure must have a unit cell with $a_{o}=10.392 \AA, b_{o}=5.196 \AA$, $c_{o}=4.252 \AA, \alpha=89.8^{\circ}, \beta=87.1^{\circ}$, and $\gamma=120^{\circ}$.

Summarizing the above results, the $\beta^{\prime}$ structure is thought to be a distorted h.c.p. structure in which the $c$-axis inclines about $3^{\circ}$ from the normal to the basal plane.

\section{Acknowledgments}

The author wishes to thank Professor H. Mitani and Professor. S. Kachi, Kyoto University, for their constant interest and encouragement, Professor S. Yoshioka for providing facilities for $\mathrm{X}$-ray investigations, and Mr. S. Saito for helpful discussions about this work. 